\title{
"Operation Cataract": a means of reducing waiting lists for cataract operations
}

\author{
Hugh F Thomas, Robin H J Darvell, Claire Hicks
}

Canterbury and Thanet Health Authority, Ramsgate

Hugh F Thomas, $\mathrm{MB}$, project manager

\section{Kent and Canterbury Hospital, Canterbury Robin H J Darvell, FRCS, consultant ophthalmologist}

IMPACT Foundation, Lindfield, West Sussex Claire Hicks, director

Correspondence to: Dr H F Thomas, Princess Margaret Hospital, Swindon, Wiltshire.
In 1986 there were 58000 people in England and Wales on ophthalmic waiting lists, most awaiting operations to remove cataracts.' Although $97 \%$ of these operations were classified as non-urgent, $17 \%$ of the patients had been waiting for over a year. Most patients awaiting ophthalmic operations are elderly, and many have other disabilities that are further exacerbated by poor vision. By March 1988 the waiting lists for ophthalmic operations in England and Wales had increased to 66000 .' The size of the waiting list varies widely among districts, ranging from a few to over 1000 patients. In a fifth of districts a quarter of the patients have been on the waiting list for over a year. If waiting lists were frozen - that is, no new cases were added-it would take half of the district health authorities more than six months at present operating rates to clear the current backlog.

After reviewing the British figures Sir John Wilson, president of the International Agency for the Prevention of Blindness and chairman of the IMPACT Foundation, who pioneered "eye camps"- a means of doing many operations in a fairly short time - in India and Africa, suggested that an eye camp was needed in southern England." This suggestion was taken up by Worthing District Health Authority, which in partnership with the IMPACT Foundation undertook "Operation Cataract" in 1987.

The proportion of residents aged over 65 is much greater in Canterbury and Thanet health district $(22 \%)$ than in England and Wales overall (15\%). In August 1988,474 patients were awaiting ophthalmic surgery in the district, of whom 217 were on Thanet's waiting list for removal of cataracts. The district health authority, after consultation with local ophthalmologists and the IMPACT Foundation, decided to carry out its own Operation Cataract to reduce this number, and this was done over 10 days in November 1988. We describe here how the scheme was organised and conducted.

\section{Organisation}

PRELIMINARY PLANNING

The district general manager established a working group of 13 people, comprising a project manager (HFT); a clinical coordinator (RHJD); three consultant ophthalmologists; a senior house officer in ophthalmology; the district and unit general managers; a theatre sister and a theatre manager; a "hotel sister"; a nursing officer; and a representative from IMPACT $(\mathrm{CH})$. The group drew up a detailed description of the project after discussions with the IMPACT Foundation and staff who had participated in the Worthing project.

\section{SELECTING A HOTEL}

The project manager and hotel sister visited numerous hotels and other establishments with large scale accommodation - for example, the university in

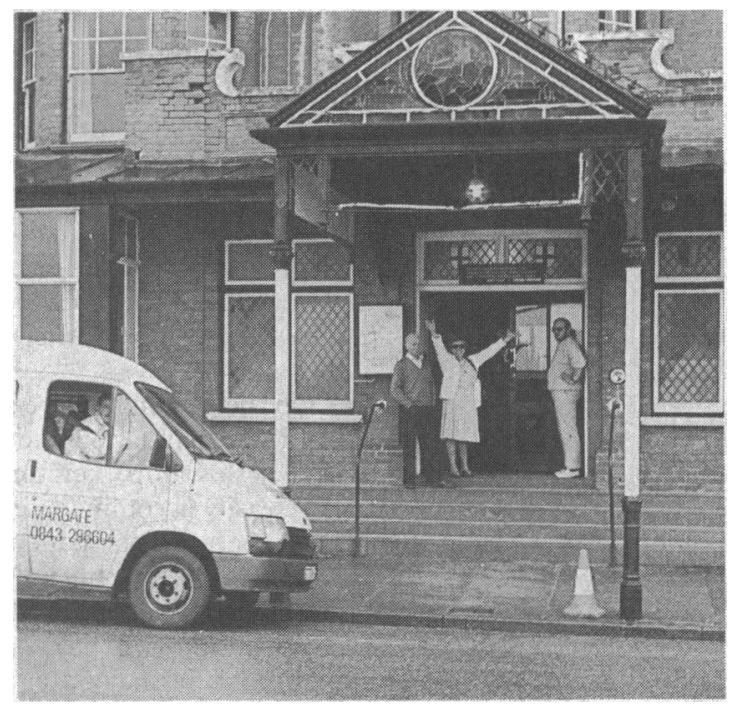

Arrival at "hospital" by minibus

Canterbury, colleges, and military barracks - to check their suitability and availability and the prices they would charge for the proposed scheme. No suitable accommodation close to the ophthalmology theatre in Canterbury was available, and a Butlins hotel in Cliftonville, on the coast $29 \mathrm{~km}$ away, was chosen. This offered patients single or double rooms on one floor with exclusive use of the restaurant and other facilities. The cost per person was under $£ 70$ for four nights' full bed and board. The accommodation was checked by the local fire department, the local police arranged to make parking space available, and the local planning department was notified of this temporary NHS scheme. A dedicated telephone line was also installed at the hotel for the duration of the project.

\section{SELECTING PATIENTS}

A target of 100 operations was set. It was decided to give priority to patients who had been on the district's waiting list for an operation for cataract for the longest time. Each patient's general practitioner was sent a short letter describing the proposed scheme and asking whether the patient would be suitable for inclusion. Exclusion criteria included poorly controlled diabetes mellitus, severe immobility, severe dementia, and recent or current illness that would make an operation inadvisable. In addition, the consultant coordinator reviewed the patients' case notes to check that they were suitable for the scheme. Of the 217 patients on Thanet's list, 26 were no longer eligible (having moved away, had the operation elsewhere, died, etc); 60 were judged to be unsuitable ( 36 by either their general practitioner or the ophthalmologist and 24 by both); and the remaining 131 were considered suitable. Three patients from Canterbury who had been waiting for up to 11 months were also selected. 
The eligible patients were sent a short letter des- cribing the scheme and a reply slip (with prepaid envelope) on which they were asked to indicate whether they wished to be considered for inclusion in the scheme, any current medical problems, and their availability on the proposed dates of the scheme. Only three patients declined the offer, five said that they were unavailable, and four could not be contacted. The 100 patients selected comprised 72 women (mean age 73.7 years) and 28 men (mean age 69.9 years). Daily operation lists were then drawn up and patients sent their dates of admission six weeks in advance. Fifteen patients agreed to be placed on a reserve list and to be available to attend at short notice.

\section{HOTEL ARRANGEMENTS}

Patients were asked to report to the hotel on the evening before the operation. Voluntary drivers provided transport by car if this was requested. The Women's Royal Voluntary Service arranged admission and took patients to their rooms. A nursing station was set up in an executive suite, and at least two nurses were on duty throughout the project. A senior house officer in ophthalmology lived at the hotel during the project, and general medical cover for the hotel was also arranged with local general practitioners. Patients were responsible for their own drug treatments during their stay.

On the evening before surgery patients were given a medical examination and assessed ophthalmologically with a slit lamp, keratometer, and biometer. These were easily accommodated at the hotel. On the day of their operation the patients were taken by minibus to Kent and Canterbury Hospital. The minibus was driven by a voluntary driver (insured by a district health authority policy) with an experienced escort. On the return journey, after the operation, a nurse escort was provided.

During their stay at the hotel patients were encouraged to regard themselves as hotel guests, with Butlins staff and members of the Women's Royal Voluntary Service available to help if required. Visiting was unrestricted, and some relatives also stayed at the hotel during the project. Meals, with waitress service, were provided at the hotel, and the Women's Royal Voluntary Service also provided morning coffee and afternoon tea. In the evening the bar was open and entertainment was provided by resident musicians and Butlins staff.

Patients were seen daily by the ophthalmic nurses, and any problems were assessed in the hotel by an ophthalmologist. Patients were discharged three days

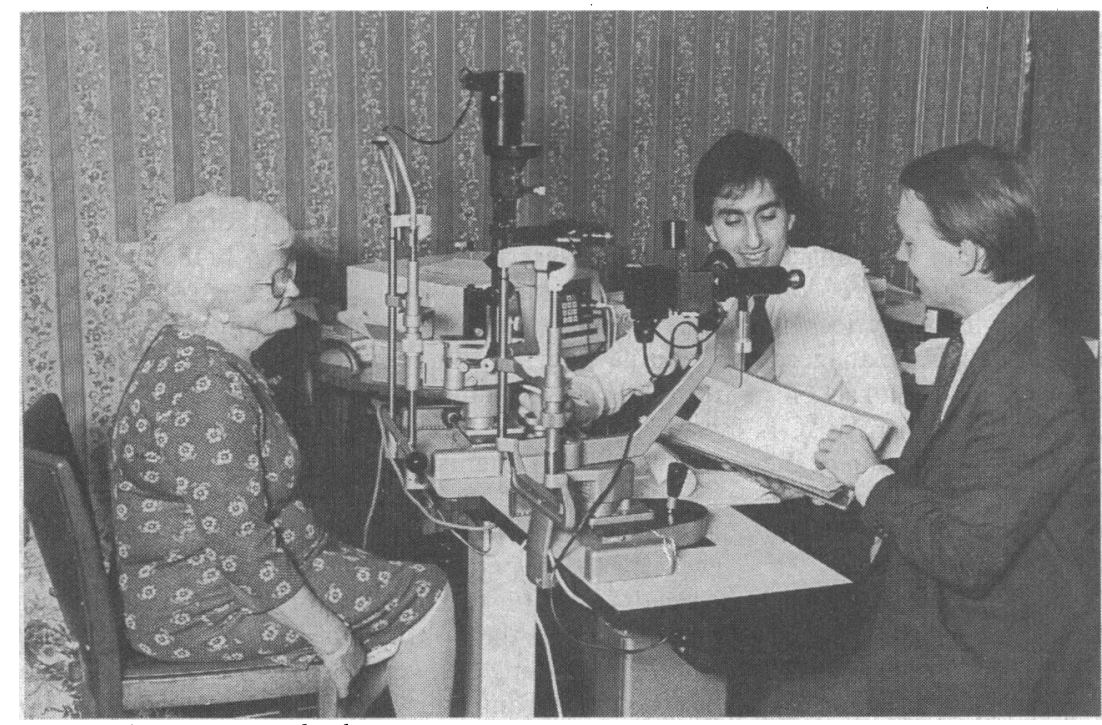

Preoperative assessment at hotel postoperatively after review by an ophthalmologist and were given appointments for special outpatient clinics, run by two consultant ophthalmologists, two and six weeks after the operation. A discharge letter was sent promptly to each patient's general practitioner, and only five patients required support from a district nurse on their return home. Two patients were transferred to the hospital eye ward at the end of the project as they required an extra few days' inpatient treatment for minor complications.

\section{HOSPITAL ARRANGEMENTS}

The hospital's eye ward was converted into a day ward with comfortable chairs, and a volunteer from the Red Cross served refreshments. The ophthalmic operating theatre was used between 8 am and $6 \mathrm{pm}$, with 16 or 17 operations being done daily over six days. Local anaesthesia was used, and surgeons worked in pairs, operating on alternate patients. Altogether four consultant surgeons (two employed solely in the district and two who had joint appointments with another district) and an experienced senior house officer did the operations, each surgeon operating on eight to 34 patients, depending on his availability. A portable sterilising unit adjacent to the operating theatre ensured an adequate supply of surgical instruments. The patients' response to local anaesthesia was favourable, and there were no anaesthetic complications. ${ }^{+}$The target of 100 operations was achieved, most of the patients (83) receiving an intraocular lens implant.

\section{Economic aspects}

In 1987, 630 cataract extractions were performed in the district. The number of operations performed in the week of Operation Cataract was therefore equivalent to the number done routinely in two months. The operating theatre was used for almost double the usual number of hours, and with the surgeons working on a rota basis there was usually less than five minutes between cases. The concentration on cataract operations meant that the dozen or so other eye operations (for example, for squints and glaucoma) usually done each week were not done. Outpatient clinics also had to be reduced by about a fifth $(60$ patients) and were run by clinical assistants and senior house officers.

The main extra cost of the project was overtime payments (£2000) for the nursing and theatre staff. Major savings to the health authority included lower hotel costs, no ambulance charges, and discount for the bulk purchase of intraocular lenses. Overall, the project cost roughly $£ 60000$, of which $£ 10000$ came from local fund raising, $£ 15000$ was provided by the IMPACT Foundation, and the rest was covered by the district health authority with a contribution from money set aside for initiatives to reduce waiting lists. The unit cost was around $£ 600$ per operation.

\section{Discussion}

The success of the scheme was due to the enthusiasm of the staff, voluntary helpers, and patients and the arrangements for postoperative care and follow up. Careful selection of the patients and prior notice of the date of admission resulted in all 100 patients turning up as arranged. Only one patient was judged unfit for surgery, and a patient from the reserve waiting list was at the hotel within two hours. The large throughput of cases halved the waiting list for cataract operations in Thanet, and 37 patients who had been waiting longer than one year were operated on. The reduction in the size of the waiting list continued to be maintained nine months later: the average waiting time for a cataract 
operation in Thanet had fallen from around a year to six months.

This type of scheme cannot replace other organisational measures to increase the regular throughput of cases, but when large waiting lists exist it is a practical way of reducing them. The details of the scheme were considered by the medical defence societies, which accepted that the arrangements provided an adequate standard of care. Using the hotel increased the bed capacity during the project from a possible 115 nights in the ward to over 400 nights. Also, it provided comfortable accommodation for the patients, nurses, and medical staff. Overall, the scheme represented an intermediate stage between day case procedures and traditional NHS treatment.

Four months after the project a postal questionnaire was sent to the patients, 95 of whom completed it. In response to the question "If you had to have another cataract operation would you prefer on the four days after the operation to stay in hospital, stay in a hotel, return home and visit a hospital daily, or return home with daily visits from an eye nurse?" 73 patients said that they would prefer to stay in a hotel as they had done in Operation Cataract. Eight said that they would prefer to be treated in hospital, four that they would prefer to go home after the operation and be treated daily at the hospital, and two that they would prefer to stay at home and have an eye nurse call daily. Eight patients did not have a preference.

Preliminary costings suggest that this type of scheme offers economic benefits to health authorities. A smaller variant, with perhaps 15 patients having operations on a Friday and then staying the weekend in a short stay ward or at a local hotel, might be used. As most patients awaiting cataract operations are over 70 years old they should be operated on as soon as possible, and innovative schemes such as the one we have described should be considered by other health districts with long waiting lists.

We thank the many organisations and people who provided practical and financial help. The participating surgeons were Mr R H J Darvell, Mr J Snow, Mr N Andrew, Mr R S Edwards, and Dr S Rassam. The photographs were provided by David Rogers.

\section{College of Health. Guide to hospital waiting lists. London: College of Health, 1987. \\ 2 College of Health. Guide to hospital waiting lists. London: College of Health, 1989. \\ Wilson J. Clearing the cataract backlog. Brf Ophthalmol 1987;71:158-60. \\ Rassam S, Thomas HF. Local anaesthesia for cataract surgery. Lancet 1989:i:110-1. \\ (Accepted 15 August 1989)}

\section{How To Do It}

\section{Look after a visiting speaker}

\section{Patrick Hoyte}

In the course of my work for a medical defence organisation I have lectured around 150 times over the past five years. Some of the audiences have been non-medical-for example, health economists, nurses, administrators - and some have been students, but most of my speaking engagements have been to medical audiences of one sort or another - postgraduate societies, BMA divisions, courses for trainee general practitioners, courses for family planners, specialist symposia.

Anyone accustomed to this sort of regular lecture circuit will be well aware of the immense variety of venues, hosts, and hospitality. While the venue itself may not be too important, provided one has been given the information to find it at all, some standards of hospitality leave a lot to be desired; although I am happy to say that the really bad examples are very much in the minority.

\section{Two disasters ...}

In February 1988 I was asked to speak to an evening meeting of a medical group in the midlands. I specifically asked the organiser for a slide projector to be made available and went ahead with travel arrangements, including a hotel booking. When I arrived at the venue after a $97 \mathrm{~km}$ drive, I found that the meeting had been cancelled because there was no projector and that the organiser had sent only a deputy to apologise. Given an audience I could, of course, have spoken perfectly well without visual aids but was not consulted, although the cancellation had been announced only earlier the same day. No offer of a lecture fee or travelling or subsistence expenses was made.

Six months previously I had spoken to a specialist symposium at a major teaching hospital. There was no one to meet me when I arrived as the organiser was listening to the previous speaker. The promised meal was almost all gone and was in any case cold, and there were no clean plates, cups, or cutlery. The previous speaker exceeded his time by about half an hour, and it was another 20 minutes before the visual aids (in this case a video recorder) could be made to work for my own presentation. Even though it was an evening meeting, no lecture fee or travelling expenses were paid.

\section{$\ldots$ and a triumph}

The following evening I was contracted to speak to a postgraduate society in Lincolnshire. A map of the town and of the hospital were sent to me, and a parking space was set aside; the organiser and the postgraduate secretary were waiting in the doorway to greet me; I was offered an excellent meal and choice of drinks and placed with pleasant company; I was even shown the "gents" without having to ask. The meeting itself went well, the large audience asked a lot of stimulating questions, and informal discussion went on for some time after that. A lecture fee and travelling expenses were paid, and I received a pleasant "thank you letter" from the postgraduate tutor.

\section{Do's and don'ts}

The examples I have given are clearly opposite ends of a large spectrum, but I do not doubt that the "disaster" organisers would have been quick to criticise if my presentations had attained only the standards they apparently set for themselves. I therefore put forward the following slightly tongue-incheek aide-mémoire for the benefit of those who wish to invite a visiting speaker and who want to look after 